\title{
What is an unacceptable light level for direct laryngoscopy?
}

\author{
Andrew D. Milne, MD · Paul Brousseau, RT
}

Received: 4 June 2009/Accepted: 11 June 2009/Published online: 10 July 2009

(C) Canadian Anesthesiologists' Society 2009

\section{To the Editor,}

Optimal lighting level may be crucial to successful tracheal intubation. However, the minimum light level required for direct laryngoscopic intubation has not been clearly defined using a standardized method of testing. Two prior studies have reported that the minimum luminance or illuminance level required for intubation is approximately 100 candela $\cdot \mathrm{m}^{-2}$ or 900 Lux, respectively. ${ }^{1,2}$ In this letter, we report an alternative calculation of the minimum acceptable laryngoscope lighting level. Over a 9-month period, our quality control office collected 11 paired laryngoscope blades and accompanying handle sets that anesthesia staff had rejected from use in the operating room due to poor or insufficient light levels. The illuminance level for each of these matched sets (Heine Classic ${ }^{\circledR}$ fibreoptic stainless steel Macintosh \#3 and \#4 blades with $2.5 \mathrm{~V}$ handle/battery packs) was tested immediately as received from the operating room using a light-testing apparatus previously validated at our institution. ${ }^{3}$ The illuminance of these 11 rejected sets ranged from 360 to 850 Lux with a mean output of $597 \pm 160$ Lux ( \pm 1 SD). In comparison, a new blade and handle set of this configuration normally produces approximately 5000 Lux. However, this maximal lighting level is often not maintained in the clinical setting due to battery depletion or blade deterioration secondary to repeated use and cleaning. Although our data do not directly assess the exact minimum threshold of light requirement for direct laryngoscopic intubation, it does indirectly support the results of prior studies in determining a minimum or unacceptable light level. In the absence of a Canadian Standards Association/International Organization for Standardization (CSA/ISO) standard, a minimum laryngoscope lighting level of 600-900 Lux may be useful for quality control purposes.

Competing interests None declared.

\section{References}

1. Skilton RW, Parry D, Arthurs GJ, Hiles P. A study of the brightness of laryngoscope light. Anaesthesia 1996; 51: 667-72.

2. Cheung $K W$, Kovacs $G$, Law JA, Brousseau P, Hill W. Illumination of bulb-on-blade laryngoscopes in the out-of-hospital setting. Acad Emerg Med 2007; 14: 496-9.

3. Brousseau P, Hung O, Law A, Levangie D, Cheverie R. Portable laryngoscope light intensity measurement apparatus. Can J Anesth 2004; 51: 47 (abstract).

\footnotetext{
A. D. Milne, MD ( $\square)$

Dalhousie University, Halifax, NS, Canada

e-mail: admilne@dal.ca

P. Brousseau, RT

QEII Health Sciences Centre, Halifax, NS, Canada
} 